\title{
Does size matter? - a population-based analysis of malignant pleural mesothelioma
}

\author{
Jiaxi He $\mathrm{He}^{1,2,3,4 \#}$, Songhui $\mathrm{Xu}^{1 \#}$, Hui Pan ${ }^{2,3,4}$, Shuben $\mathrm{Li}^{2,3,4}$, Jianxing $\mathrm{He}^{2,3,4}$ \\ ${ }^{1}$ Department of Pathology, University of Maryland Baltimore, School of Medicine, Baltimore, MD, USA; ${ }^{2}$ Department of Thoracic Surgery, The \\ First Affiliated Hospital of Guangzhou Medical University, Guangzhou, China; ${ }^{3}$ Guangzhou Institute of Respiratory Disease \& China State Key \\ Laboratory of Respiratory Disease, Guangzhou, China; ${ }^{4}$ National Clinical Research Center for Respiratory Disease, Guangzhou, China \\ Contributions: (I) Conception and design: J He, J He, S Li; (II) Administrative support: J He, S Li; (III) Provision of study materials or patients: J He, \\ S Xu, H Pan; (IV) Collection and assembly of data: J He, S Xu, H Pan; (V) Data analysis and interpretation: J He, S Xu, H Pan; (VI) Manuscript \\ writing: All authors; (VII) Final approval of manuscript: All authors. \\ "These authors contributed equally to this work. \\ Correspondence to: Shuben Li, Jianxing He. Department of Thoracic Surgery, the First Affiliated Hospital of Guangzhou Medical University, \\ Guangzhou, China. Email: 13500030280@163.com; hejianxing@hotmail.com.
}

Background: The $8^{\text {th }}$ edition staging system for malignant pleural mesothelioma (MPM) has been proposed. The size of tumor is not taken into consideration. We intend to elucidate the prognostic value of the size of MPM and evaluate the current staging system via the data of SEER database.

Methods: All cases of primary MPM were identified and extracted from the SEER database during the period of 2004-2016. The endpoints were overall survival (OS) and cancer-specific survival (CSS) which were analyzed using Kaplan-Meier method. Log-rank test and Cox regression were utilized to identify the prognostic factors.

Results: A total of 2,138 patients were included in the primary cohort. The 1-, 3- and 5-year survival rates of MPM were 39.4\%, 11.8\% and 3.8\%. Older, male and advanced stage patients accounted for larger proportion of the cohort. Besides tumor extension, lymph node involvement and metastatic status, tumor size, pathological type and differentiation grade were significant prognostic factors. In the stratified analysis of tumor extension, size is a significant prognostic factor in T2 patients and indicates inferior survival outcomes. Surgery, chemotherapy and radiation can increase both OS and CSS in MPM patients. Triple combination treatments showed a superiority to other treatments.

Conclusions: Tumor size matters in the prognosis of MPM especially in the early stage of MPM patients. The adjusted TNM staging system incorporating tumor size has better accuracy than the $8^{\text {th }}$ edition IMIG system. However, some stages had not been fully identified. More cases of early stages are warranted for essential revision.

Keywords: Malignant pleural mesothelioma (MPM); tumor size; prognosis; SEER; outcomes; stage

Submitted Oct 09, 2019. Accepted for publication Mar 06, 2020.

doi: $10.21037 /$ tlcr-19-488

View this article at: http://dx.doi.org/10.21037/tlcr-19-488

\section{Introduction}

The malignant pleural mesothelioma (MPM) is a rare and aggressive type of pleural malignancies. The incidence of MPM is proved to be highly related to the exposure to asbestos which accounts for more than $80 \%$ cases (1).
The symptoms of MPM are concealed. As a result, large proportion of patients are diagnosed as advanced diseases with only $8 \%$ of 5 -year survival rate $(2,3)$. A validated staging system is crucial for disease evaluation, treatment selection and follow-up strategy. A number of staging systems of MPM had been previously proposed and utilized 
in some clinical retrospective studies regionally until 1990s (4). However, few of them were population-based or established as TNM (tumor, lymph node and metastasis) system. The most generally used staging system is the $7^{\text {th }}$ edition TNM stage which is developed by the International Association for the Study of Lung Cancer (IASLC) and the International Mesothelioma Interest Group (IMIG) (5). However, it has not been widely accepted due to the absence of large-cohort validation.

The IASLC Staging Committee has performed a validation study using the data from multiple centers and proposed the $8^{\text {th }}$ edition of MPM staging system (6-8). The result reports some essential revisions in $\mathrm{T} / \mathrm{N}$ categories and the new groupings. Unlike other solid tumor staging system, tumor size of MPM is not taken into consideration in T category. Therefore, we intend to perform a study on the Surveillance, Epidemiology, and End Results Database (SEER) to analyze the prognostic factors of MPM and evaluate the prognostic effect of size.

\section{Methods}

\section{Data Source}

This study was performed using the data from SEER database, which was sponsored by National Cancer Institute and covered approximately $28 \%$ of US population (9). The database we used in the study was the SEER 18 Registry Custom Data (with additional treatment fields), Nov 2018 Sub and (2000-2016). The patients diagnosed as malignant mesothelioma including the pathological types of fibrous, epithelial, biphasic and non-other specific mesothelioma (ICD-0-3=9050-9053) in the primary site of pleural (SEER primary site code $=38.4$ ) were identified. The identified cases included the data of age at diagnosis, sex, race, surgery, radiation, chemotherapy, tumor size, tumor extension, lymph node involvement, metastasis status, histology, grade, vital status, overall survival interval and cancer-specific survival interval. Cases without data of tumor features were excluded after discussion. The selection process of primary cohort was demonstrated in Figure 1.

\section{Definitions of data in SEER}

The tumor features recorded in SEER were defined by CS coding system (CS Extension of Pleural) (10). We categorized the primary cohort by a general tumor extension classification based on the descriptions of coding system and IMIG staging system. We defined E1-E4 as the same tumor involvement as T1-T4 in the $8^{\text {th }}$ IMIG staging system.

In accordance to the current staging system, the pathological lymph node involvement was categorized as follow: Nx, lymph node involvement unknown; N0, no regional lymph node involvement; N1, intrathoracic lymph node involvements including ipsilateral bronchopulmonary and/or hilar lymph node; N2, subcarinal, ipsilateral internal mammary, mediastinal lymph nodes, or the peri-diaphramatic lymph nodes; N3, distant lymph node involvement including contralateral mediastinal, contralateral internal mammary, or hilar area, and/or the ipsilateral supraclavicular or scalene area. Metastasis status were defined as M0 (metastasis-free) and M1 (distant metastasis).

\section{Statistical analysis}

Overall survival (OS) and cancer-specific survival (CSS) were estimated and analyzed by the Kaplan-Meier (KM) method and the log-rank test. Univariate and multivariate survival analyses were conducted using the Cox proportional hazards model. A Cox multivariate model was made including variables which were statistically significant in univariate analysis or considered as clinically significant. The prognostic effect of tumor size was analyzed in different tumor extension groups.

Treatments were categorized as surgery, chemotherapy and radiation groups. Besides, those who had received more than single treatment were classified in the double or triple combination groups.

The Kaplan-Meier and Cox regression were performed using the software of SPSS 25.0 and GraphPad Prism 5 . The concordance to the actual survival of each stage model was evaluated by concordance index (C-index) using $\mathrm{R}$ (Version 3.4.1, R Core Team) (11). The comparison between two staging systems was performed using "rcorrp. cens" method and likelihood ratio test via "Hmisc" and "lmtest" packages in $\mathrm{R}(12,13)$. The statistical difference was considered as significant when $\mathrm{P}<0.05$. All tests were two-sided.

\section{Result}

\section{Clinical characteristics of MPM}

A total of 12,516 patients with pleural malignancies 


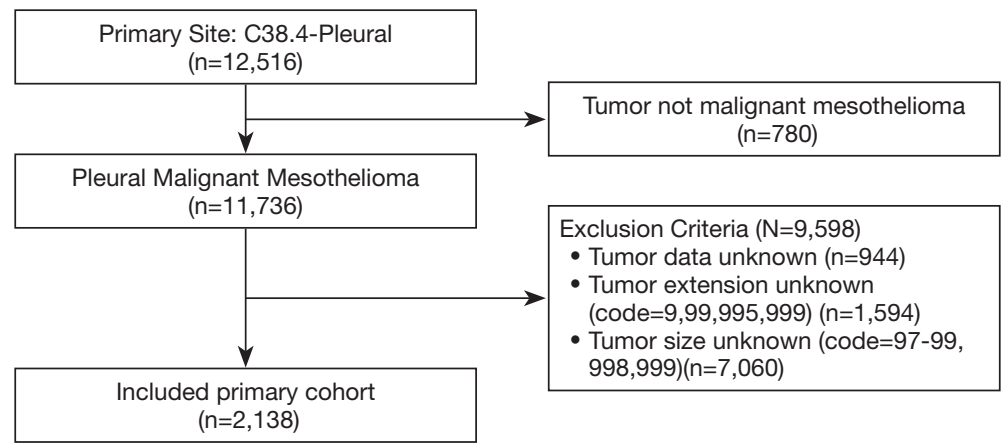

Figure 1 The diagram of primary cohort selection process.

were identified from SEER database. Among them, 11,736 patients diagnosed as malignant pleural mesothelioma were included in the original cohort. After the selection process, 2,138 patients were finally included in the primary cohort (Figure 1). According to the $8^{\text {th }}$ edition IMIG staging system, 224 patients was stage IA, 313 in stage IB, 140 in stage II, 53 in stage IIIA, 908 in stage IIIB and 291 in stage IV. The mean age of the primary cohort was $69.02 \pm 11.56$-year-old ranging from 24 to 96 . No difference of age was observed among the stages. More patients were in the advance stages at the diagnosis. More patients were diagnosed as poorly and undifferentiated grades. More male patients were diagnosed MPM than female patients in each stage $(\mathrm{P}<0.05)$. Referring to human race, the number of white patients which was $91.1 \%$ of primary cohort outweighed other races. T4 and N0 patients accounted for the largest proportion in $\mathrm{T}$ and $\mathrm{N}$ categories, respectively (Table 1).

\section{Frequency and survival of MPM}

Based on SEER data, the frequency of MPM patients increased smoothly from $0.5 \%$ in 1973 and reached the highest of $1.0 \%$ in 1993. Since then, it fluctuated in the range of $0.7 \%$ to $1.0 \%$ from 1994 to 2013 (Figure S1).

In order to elucidate the prognosis of MPM, we performed the overall survival (OS) and cancer-specific survival (CSS) analyses both in original cohort and the primary cohort. The median survival of both cohort in OS and CSS were 9 and 10 months. The 1-, 3- and 5-year survival rates of OS in primary cohort were $39.4 \%, 11.8 \%$ and $3.8 \%$, which were consistent with the original cohort (36.7\%, 9.6\% and 4.8\%) (Figure 2). The 1-, 3- and 5-year survival rate of CSS in primary cohort were $42.3 \%, 14.2 \%$ and $8.7 \%$, which were also similar to the original cohort $(43.2 \%, 12.1 \%$ and $6.6 \%)$ (Figure 2).

\section{Prognostic factors of MPM}

In the univariate analysis, the results indicated that some clinical characteristics were significant prognostic factors of MPM including age, sex. Older patients had worse prognosis than the younger patients $(\mathrm{HR}=1.027,95 \% \mathrm{CI}$ : $1.023-1.032, \mathrm{P}<0.001)$. On the other hand, female patients had better survival outcomes than male ( $\mathrm{HR}=0.724$, 95\% CI: 0.647-0.81, $\mathrm{P}<0.001)$. However, the human race showed no effect on the prognosis (Table 2).

Referring to the tumor features, the outcomes of epithelial histology was the best in four histology subtypes. The biphasic was slightly worse than the epithelial type. The sarcomatoid histology and mesothelioma no other specific type (NOS) were associated with poor prognosis, of which the median survivals were 7 and 8 months. The sarcomatoid histology showed superiority of survival to NOS after 14 months (HR $=0.849,95 \%$ CI: 0.736-0.979, $\mathrm{P}=0.024)$ (Table 2).

Besides, tumor differentiation grade, size, extension, lymph node involvement and metastasis status were negative prognostic factors. Among them, undifferentiated grade $(\mathrm{HR}=2.75,95 \% \mathrm{CI}$ : 1.682-4.497, $\mathrm{P}<0.001)$, N2 (HR $=1.608,95 \% \mathrm{CI}: 1.227-2.108, \mathrm{P}=0.001)$ and metastasis (HR $=1.472,95 \%$ CI: $1.29-1.679, \mathrm{P}<0.001)$ were associated with the worst prognosis with only 6,5 and 6 months of median survival, respectively. The median survival of T4 was 8 months, which was worse than T1 with 11 months (HR $=1.375,95 \%$ CI: $1.215-1.557, \mathrm{P}<0.001$ ).

Chemotherapy, radiation and surgical treatments were able to improve the prognosis of MPM patients (Table 2). In the surgical treatment analysis, we noticed that both local destruction ( $\mathrm{HR}=0.48,95 \% \mathrm{CI}: 0.422-0.546, \mathrm{P}<0.001)$ and radical surgery ( $\mathrm{HR}=0.487,95 \% \mathrm{CI}: 0.425-0.558, \mathrm{P}<0.001$ ) were significantly better than non-surgery groups, which 
Table 1 The characteristics of patients with malignant pleural mesothelioma in different stages

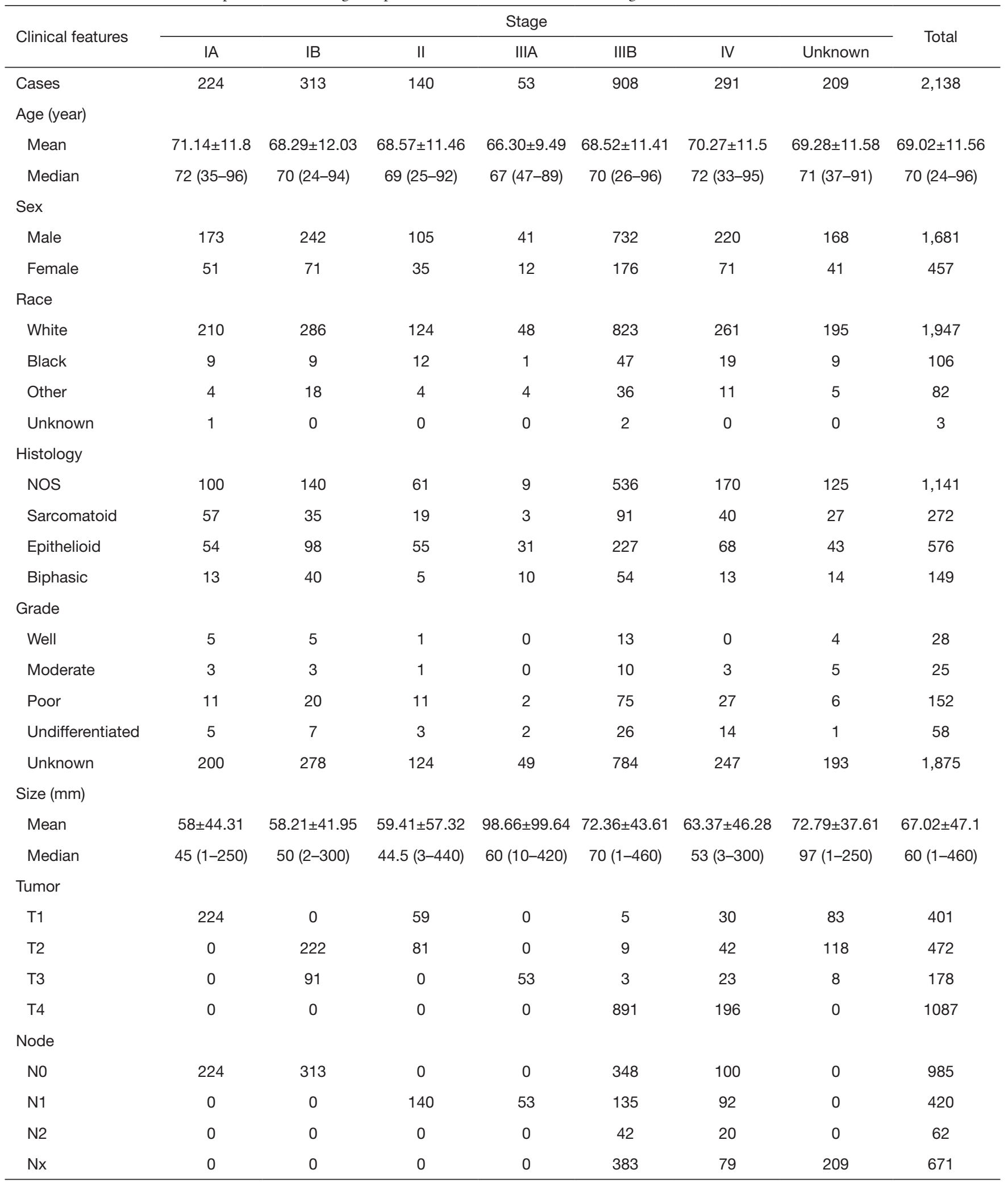

Table 1 (continued) 
Table 1 (continued)

\begin{tabular}{|c|c|c|c|c|c|c|c|c|}
\hline \multirow{2}{*}{ Clinical features } & \multicolumn{7}{|c|}{ Stage } & \multirow{2}{*}{ Total } \\
\hline & IA & IB & II & IIIA & IIIB & IV & Unknown & \\
\hline \multicolumn{9}{|l|}{ Surgery } \\
\hline No & 118 & 125 & 81 & 19 & 380 & 234 & 70 & 1,027 \\
\hline Local destruction & 56 & 92 & 27 & 11 & 147 & 42 & 26 & 401 \\
\hline \multicolumn{9}{|l|}{ Radiation } \\
\hline No & 186 & 237 & 115 & 29 & 655 & 217 & 160 & 1,599 \\
\hline Yes & 34 & 73 & 24 & 20 & 230 & 71 & 39 & 491 \\
\hline Yes & 72 & 146 & 68 & 34 & 337 & 142 & 56 & 855 \\
\hline
\end{tabular}
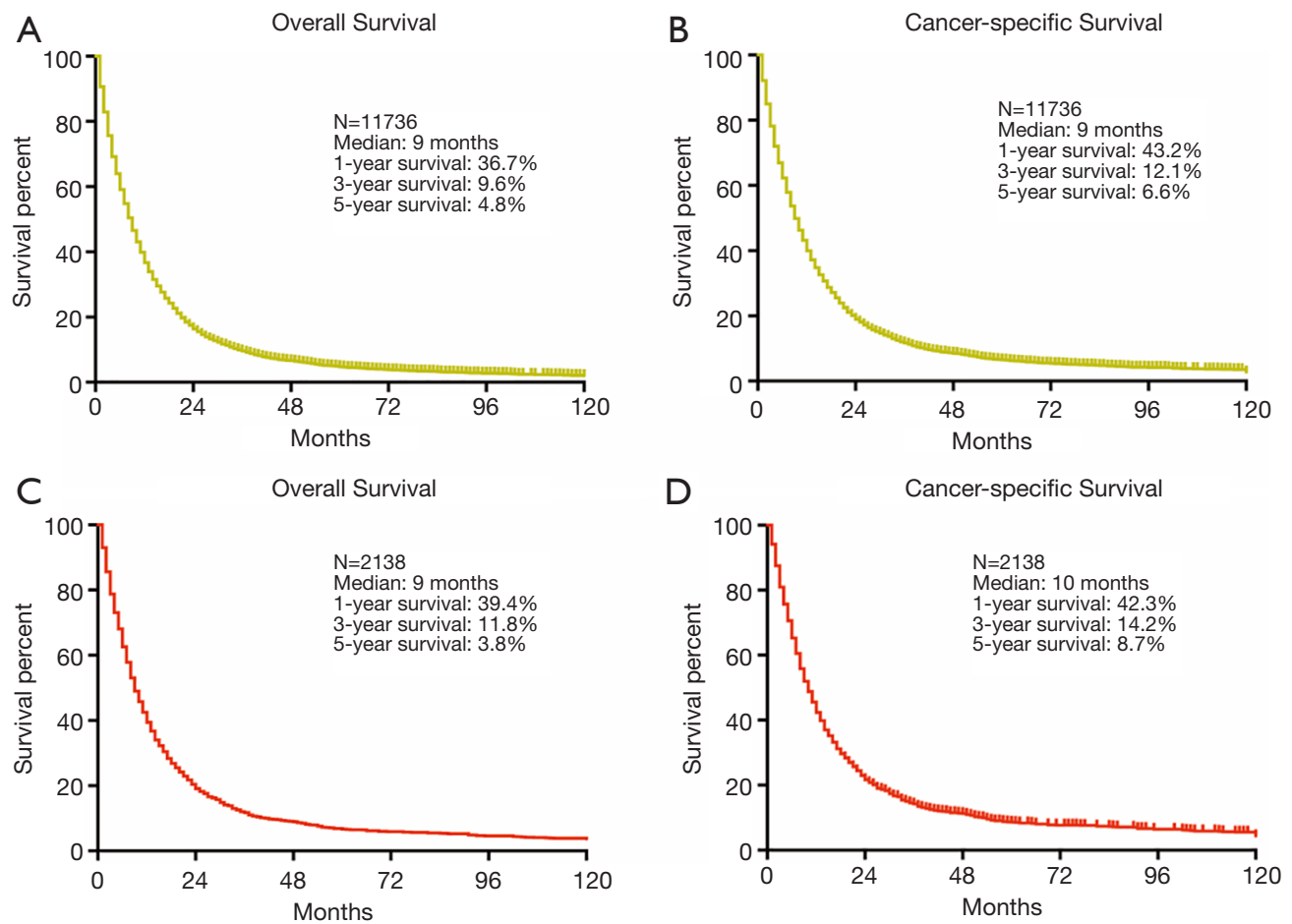

Figure 2 The frequency of malignant pleural mesothelioma in SEER database The survival outcomes of original and primary cohorts. (A) Overall survival of original cohort; (B) cancer-specific survival of original cohort; (C) overall survival of primary cohort; (D) cancer-specific survival of primary cohort. 
Table 2 The univariate and multivariate analysis of prognostic factors in MPM patients

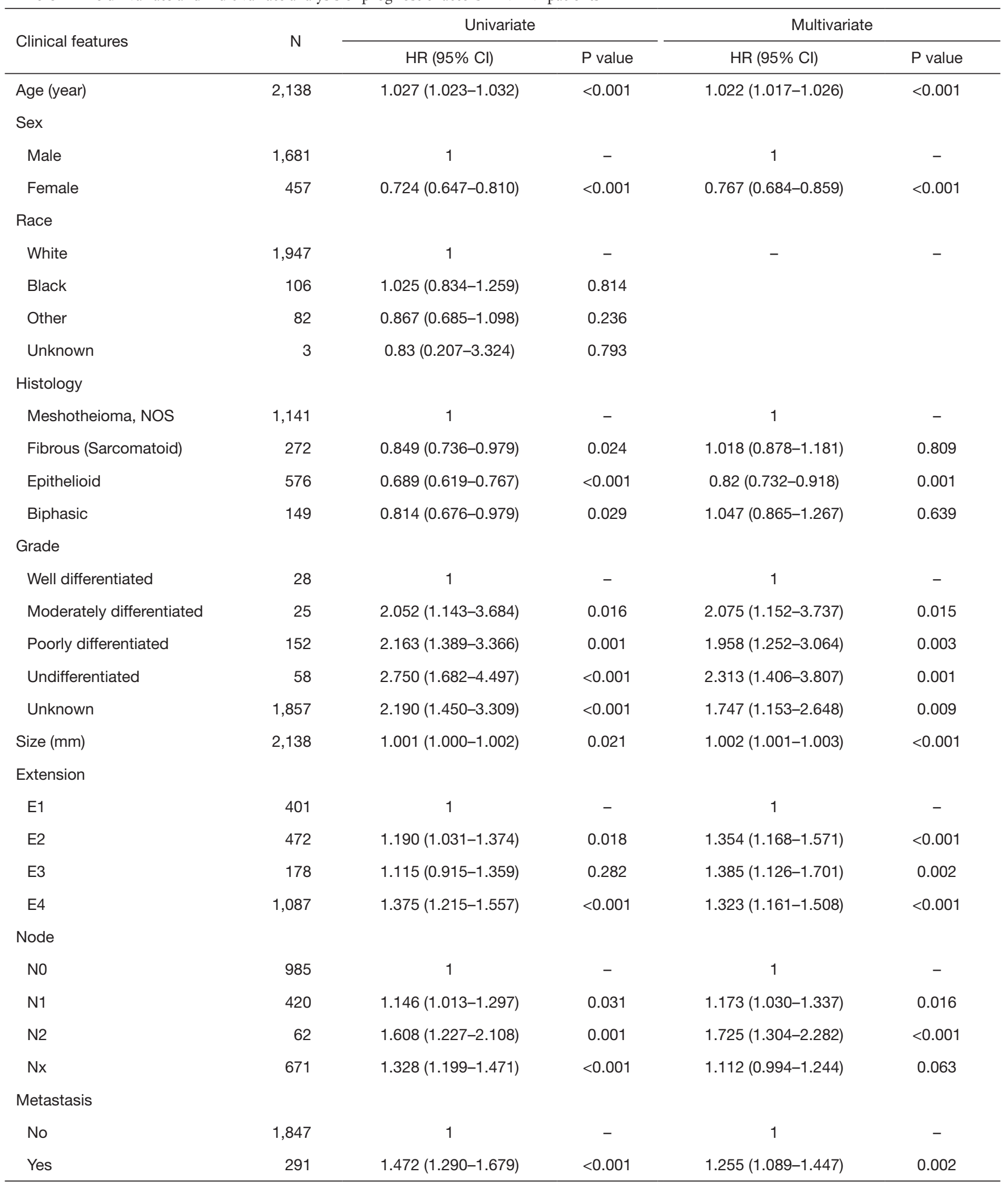

Table 2 (continued) 
Table 2 (continued)

\begin{tabular}{|c|c|c|c|c|c|}
\hline Clinical features & $\mathrm{N}$ & \multicolumn{2}{|c|}{ Univariate } & \multicolumn{2}{|c|}{ Multivariate } \\
\hline \multicolumn{6}{|l|}{ Surgery } \\
\hline No & 1,027 & 1 & - & 1 & - \\
\hline Local destruction & 401 & $0.48(0.422-0.546)$ & $<0.001$ & $0.558(0.486-0.641)$ & $<0.001$ \\
\hline Unknown & 378 & $0.966(0.857-1.089)$ & 0.575 & $0.92(0.8-1.059)$ & 0.248 \\
\hline \multicolumn{6}{|l|}{ Radiation } \\
\hline No & 1,599 & 1 & - & 1 & - \\
\hline Yes & 491 & $0.88(0.791-0.979)$ & 0.019 & $0.966(0.864-1.079)$ & 0.537 \\
\hline No/Unknown & 1,283 & 1 & - & 1 & - \\
\hline Yes & 855 & $0.799(0.728-0.876)$ & $<0.001$ & $0.781(0.706-0.864)$ & $<0.001$ \\
\hline
\end{tabular}

had median survival of 14,16 and 7 months, respectively. The triple combination treatment provided the best survival outcomes while patients received no treatment had the worst (23 vs. 5 months, HR $=2.216,95 \%$ CI: $1.845-2.662$, $\mathrm{P}<0.001)$. However, no significant difference of OS was observed between surgery and combined treatment group (HR $=1.059,95 \%$ CI: 0.823-1.362, $\mathrm{P}=0.656$ ) (Figure S2).

The results of multivariate analysis showed that age, gender, histology, differentiation grade, tumor size, $\mathrm{T}$ category, $\mathrm{N}$ category, metastasis status, surgery and chemotherapy were independent prognostic factors, except radiation (Table 2).

\section{Prognostic effect of tumor size}

In the univariate and multivariate analysis, it showed that tumor size was an independent negatively prognostic factor. Therefore, the prognostic effect of size was evaluated in each tumor extension subgroups. The results showed tumor size had no significant prognostic effect in E1, E3 and E4 subgroups. Nevertheless, it had significant effect on survival in E2 (Data not shown).

\section{Staging systems of MPM}

The curve of hazard ratio (HR) of each size intervals in E2 were fitted by using Lowess smoother (Figure S3). It showed that the cutpoint was at the $3 \mathrm{rd}$ subgroup $(\leq 3 \mathrm{~cm})$ and the HR rose remarkably from the 7 th subgroup $(>7 \mathrm{~cm})$. On the other hand, the tertiles points of sizes in $\mathrm{E} 2$ which were 3 and $69.5 \mathrm{~cm}$, which were consistent with the cutpoints. The KM curves showed the median survival of three groups were 19, 12 and 8 months, respectively $(\mathrm{P}=0.015)$ (Figure $3 A$ ). The $\mathrm{E} 1$ and $\mathrm{E} 2 \leq 3 \mathrm{~cm}$ patients had no difference in clinical outcomes, the same phenomenon was observed in the comparison between E2 $>7 \mathrm{~cm}$ and E3 patients. After verifying the breaking point position in 5,6 and $7 \mathrm{~cm}$, the largest difference was observed at $7 \mathrm{~cm}$. Therefore, the new $\mathrm{T}$ category was proposed as T1: $\mathrm{E} 1, \mathrm{E} 2 \leq 3 \mathrm{~cm}$; T2: E2 3-7 cm; T3: E2 >7 cm, E3; T4: E4 (Figure 3B).

In the $\mathrm{N}$ category, we noticed $\mathrm{N} 1$ and $\mathrm{N} 2$ had no difference in OS. Therefore, we collapsed N1 and N2 into new $\mathrm{N} 1$ and reclassified $\mathrm{N} 3$ as new $\mathrm{N} 2$ in concordance to the $8^{\text {th }}$ IMIG staging system. According to the upcoming system, despite of any other tumor features, T4 or N2 patients were categorized as Stage IIIB. In the survival analysis of Stage IIIB, it indicated that T4N0-1M0 had better outcomes than TanyN2M0 and M1 $(\mathrm{P}<0.001)$. Therefore, any N2 patients should be reclassified to Stage IV. In Stage II, no difference of survival outcome was observed among T1-2N1M0 and T3N0M0 of which the median survival were 11 months. As a result, the staging system was adjusted as follow: Stage IA (T1N0M0), Stage IB (T2N0M0), Stage II (T1-2N1M0, T3N0M0), Stage IIIA 

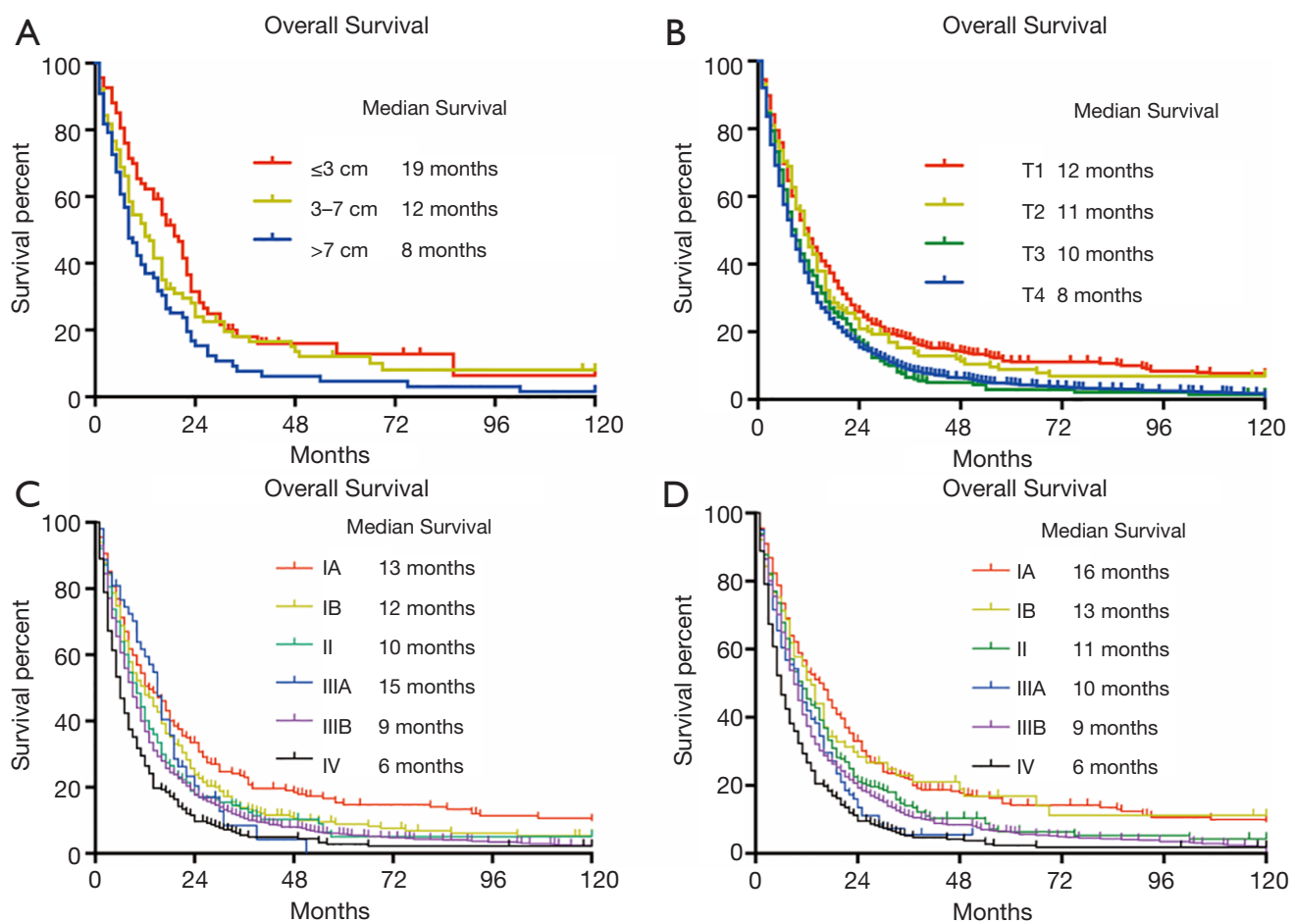

Figure 3 The survival outcomes of different stages. (A) Overall survival of different size cutpoints interval in T2; (B) overall Survival of the adjusted T category; (C) overall survival of primary cohort classified by the 8th edition IMIG system; (D) overall survival of primary cohort classified by the adjusted staging system.

(T3N1M0), Stage IIIB (T4N0-1M0) and Stage IV (any N2, M1). The prognosis of each previous and adjusted stages was shown in Figure 3C,D, respectively.

The detail of adjusted staging system was shown in Table S1. The C-indexes of the adjusted staging system, $7^{\text {th }}$ and $8^{\text {th }}$ edition of IMIG staging systems were $0.61,0.54$ and 0.58 , respectively. The tests results indicated the adjusted system was more concordant to the actual survival than other system (0.61, 0.58 and $0.54, \mathrm{P}<0.0001)$.

\section{Discussion}

MPM is one of the rare malignancies of pleura, its frequency has elevated significantly in the past 40 years. Although numbers of treatments for MPM have been developed (14-22), the prognosis of MPM is still unsatisfied with only $40 \%$ of 1 -year survival rate and no more than $10 \%$ of 3 -year survival rate. The lack of accurate evaluation scales in both clinical and pathological aspects accounts for the difficulty of treatment selection and prognosis estimation. Therefore, we performed the current study to illustrate the clinical characteristics and tumor features of MPM. Additionally, prognostic factors were identified and an adjusted staging system was proposed for better evaluation (23-26).

In the previous studies of MPM staging system, few has investigated the tumor size prognostic effect (27-32). A study has reported the thickness of tumor had impact on the survival of MPM. However, it is used to evaluate the effect of radical surgery or radiation rather than stage grouping (33). In the staging system of other solid tumors, $\mathrm{T}$ categories usually contains tumor involvement and size. IASLC recently has reported some alterations in $\mathrm{T}$ and $\mathrm{N}$ categories for the forthcoming $8^{\text {th }}$ edition MPM staging system $(6,7)$. The revision in T category is the collapsing of T1a and T1b. Although it mentions that tumor thickness is associated with survival, tumor size is still not taken into consideration in grouping (7). In our primary cohort, we notice that only tumor extension is not powerful enough to discriminate the T1-T3 patients. The similar result is reported by the IASLC study $(7,27)$. We therefore explored the weight of size in different tumor extension strata and we realized it was significant prognostic factor especially in T2 category of $8^{\text {th }}$ MPM staging system. In order to identify the cut-off value of sizes, we used two methods including 
tertiles and breakpoints of regression curve. The results of both methods showed a high consistency that sizes of $3 \mathrm{~cm}$ and $7 \mathrm{~cm}$ turned were significant determinants. The adjusted $\mathrm{T}$ category incorporating tumor size showed a better power of discrimination in early stage patients.

An exploratory study of adjusted staging system was also performed after the prognostic effect of tumor size had been identified. The previous N category of IMIG staging system is very similar to the TNM staging system of lung cancer (34). Rusch et.al. have indicated the grouping of N1$\mathrm{N} 2$ was empirical, since the lymphatic drainage pattern from $\mathrm{N} 1$ to $\mathrm{N} 2$ resembled lung cancer $(8,34,35)$. Some studies suggest the sequence of N2 lymphatic drainage in MPM is inconsistent with lung cancer (36-38). A large-scale study performed by the IASLC committee suggests the previous $\mathrm{N} 1$ and N2 categories have no survival difference and they should be collapsed into a single $\mathrm{N}$ category (6). In our cohort, we observed the same results as the previous studies. The adjusted N1 and N2 curves have clear separation. N0 has a better median survival, but shows no significant result in this study. Along with metastasis, the $8^{\text {th }}$ edition system categorizes any T4 or N2 patients as Stage IV regardless of other tumor features (8). Our data shows that only N2 shared the same survival outcome of M1 patients (Figure S4). In order to evaluate the prediction accuracy of models, C-index and two methods $(39,40)$ were used to compare the performance of each staging system. Although the C-indexes of three models were not impressive, the $8^{\text {th }}$ edition model was more accurate than the $7^{\text {th }}$, while the adjusted model was the most concordant to the actual survival.

Limitations have to be admitted in the current study. Firstly, 18F-fluorodeoxyglucose (18F-FDG) PET/CT and PET/MRI have also been proved to be determined and very helpful in diagnosing and evaluating MPM (41-43). Some researchers indicated that the metabolism of $18 \mathrm{~F}-\mathrm{FDG}$ could be used as assessment or predictive factor for responses of chemotherapy regimens $(44,45)$. Moreover, serum biomarkers also play remarkable roles in monitoring MPM. Among them, mesothelin is highly associated with the disease status (46-48). Other inflammatory cytokines and miRNA also show some effects in diagnosis $(49,50)$. However, SEER database fails to provide any radiographic or serological data. Neither clinical staging system nor further assessment of radiographic image was able to be studied in this research. Secondly, a large amount of incomplete data is eliminated during the process. Besides, the early stage patients only accounts for a small proportion of the cohort. The analysis of early stage patients might be insignificant and inconclusive owing to a small sample size. Besides, some cases of multifocal lesions could not be identified in this study. The prognosis of these cases could not be clarified with incomplete data. Thirdly, preoperative evaluation of MPM is not as easy as other solid tumor. Given the pathological features and proliferation pattern, the conventional TNM staging even incorporating tumor size is not conclusive or accurate for prognosis prediction. In addition, the current study also suggests that tumor histology subtype and differentiation grade have crucial effects in survival of MPM. A novel prediction model is warranted. Finally, surgical treatments have a predominant status in the early stages of MPM, though adverse events might happen (51-55). Multimodality treatments favor better outcomes, which are consistent with other studies (56-60). Lacking of surgical approaches or comorbidities data lead to unclear superiority of P/D or EPP.

In summary, MPM is a rare malignancy with poor prognosis. Besides tumor extension, lymph node involvement and metastasis status, the tumor size matters in clinical outcomes especially in early stage of MPM. The adjusted pathological TNM staging system incorporating tumor size in T category shows a better accuracy in survival prediction. A larger cohort with complete data is warranted to further investigate and verify the prognostic effect of tumor size in early stage of MPM.

\section{Acknowledgments}

Funding: None.

\section{Footnote}

Conflicts of Interest: All authors have completed the ICMJE uniform disclosure form (available at http://dx.doi. org/10.21037/tlcr-19-488). The authors have no conflicts of interest to declare.

Ethical Statement: The authors are accountable for all aspects of the work in ensuring that questions related to the accuracy or integrity of any part of the work are appropriately investigated and resolved.

Open Access Statement: This is an Open Access article distributed in accordance with the Creative Commons Attribution-NonCommercial-NoDerivs 4.0 International License (CC BY-NC-ND 4.0), which permits the noncommercial replication and distribution of the article with 
the strict proviso that no changes or edits are made and the original work is properly cited (including links to both the formal publication through the relevant DOI and the license). See: https://creativecommons.org/licenses/by-nc-nd/4.0/.

\section{References}

1. de Gooijer CJ, Baas P, Burgers JA. Current chemotherapy strategies in malignant pleural mesothelioma. Transl Lung Cancer Res 2018;7:574-83.

2. Kondola S, Manners D, Nowak AK. Malignant pleural mesothelioma: an update on diagnosis and treatment options. Ther Adv Respir Dis 2016;10:275-88.

3. Zhou C, Qin Y, Zhang D, et al. Clinical efficacies of gemcitabine combined with docetaxel single or plus bevacizumab as second-line therapy for malignant pleural mesothelioma. Transl Cancer Res 2018;7:48-54.

4. Petrini I, Lucchesi M, Puppo G, et al. Medical treatment of malignant pleural mesothelioma relapses. J Thorac Dis 2018;10:S333-41.

5. Cancer AJCo. AJCC Cancer Staging Manual, 7th Ed. New York, NY: Springer; 2010.

6. Rice D, Chansky K, Nowak A, et al. The IASLC Mesothelioma Staging Project: Proposals for Revisions of the N Descriptors in the Forthcoming Eighth Edition of the TNM Classification for Pleural Mesothelioma. J Thorac Oncol 2016;11:2100-11.

7. Nowak AK, Chansky K, Rice DC, et al. The IASLC Mesothelioma Staging Project: Proposals for Revisions of the T Descriptors in the Forthcoming Eighth Edition of the TNM Classification for Pleural Mesothelioma. J Thorac Oncol 2016;11:2089-99.

8. Rusch VW, Chansky K, Kindler HL, et al. The IASLC Mesothelioma Staging Project: Proposals for the M Descriptors and for Revision of the TNM Stage Groupings in the Forthcoming (Eighth) Edition of the TNM Classification for Mesothelioma. J Thorac Oncol 2016;11:2112-9.

9. Hankey BF, Ries LA, Edwards BK. The surveillance, epidemiology, and end results program: a national resource. Cancer Epidemiol Biomarkers Prev 1999;8:1117-21.

10. Collaborative Stage Data Set. Available online: http:// web2.facs.org/cstage 0205/pleura/Pleuraschema.html

11. R Core Team (2015). R: A language and environment for statistical computing. R Foundation for Statistical Computing, Vienna, Austria. Available online: http://www. R-project.org/
12. Frank E Harrell Jr, with contributions from Charles Dupont and many others. (2015). Hmisc: Harrell Miscellaneous. R package version 3.15-0. Available online: http://CRAN.R-project.org/package=Hmisc

13. Zeileis A, Hothorn T. Diagnostic Checking in Regression Relationships. R News 2002;2:7-10. Available online: http://CRAN.R-project.org/doc/Rnews/

14. Vogelzang NJ, Rusthoven JJ, Symanowski J, et al. Phase III study of pemetrexed in combination with cisplatin versus cisplatin alone in patients with malignant pleural mesothelioma. J Clin Oncol 2003;21:2636-44.

15. Weder W, Stahel RA, Bernhard J, et al. Multicenter trial of neo-adjuvant chemotherapy followed by extrapleural pneumonectomy in malignant pleural mesothelioma. Ann Oncol 2007;18:1196-202.

16. Weder W, Kestenholz P, Taverna C, et al. Neoadjuvant chemotherapy followed by extrapleural pneumonectomy in malignant pleural mesothelioma. J Clin Oncol 2004;22:3451-7.

17. Stahel RA, Riesterer O, Xyrafas A, et al. Neoadjuvant chemotherapy and extrapleural pneumonectomy of malignant pleural mesothelioma with or without hemithoracic radiotherapy (SAKK 17/04): a randomised, international, multicentre phase 2 trial. Lancet Oncol 2015;16:1651-8.

18. Thieke C, Nicolay NH, Sterzing F, et al. Long-term results in malignant pleural mesothelioma treated with neoadjuvant chemotherapy, extrapleural pneumonectomy and intensity-modulated radiotherapy. Radiat Oncol 2015;10:267.

19. Sugarbaker DJ, Richards WG, Bueno R. Extrapleural pneumonectomy in the treatment of epithelioid malignant pleural mesothelioma: novel prognostic implications of combined N1 and N2 nodal involvement based on experience in 529 patients. Ann Surg 2014;260:577-80; discussion 580-2.

20. Ambrogi V, Baldi A, Schillaci O, et al. Clinical impact of extrapleural pneumonectomy for malignant pleural mesothelioma. Ann Surg Oncol 2012;19:1692-9.

21. Rena O. Extrapleural pneumonectomy in malignant pleural mesothelioma. BMJ 2011;343:d5706.

22. Cao CQ, Yan TD, Bannon PG, et al. A systematic review of extrapleural pneumonectomy for malignant pleural mesothelioma. J Thorac Oncol 2010;5:1692-703.

23. Suzuki H, Asami K, Hirashima T, et al. Stratification of malignant pleural mesothelioma prognosis using recursive partitioning analysis. Lung 2014;192:191-5.

24. Mineo TC, Ambrogi V. Malignant pleural mesothelioma: 
factors influencing the prognosis. Oncology 2012;26:1164-75

25. Brims FJ, Meniawy TM, Duffus I, et al. A Novel Clinical Prediction Model for Prognosis in Malignant Pleural Mesothelioma Using Decision Tree Analysis. J Thorac Oncol 2016;11:573-82.

26. Rusch VW, Giroux D. Do we need a revised staging system for malignant pleural mesothelioma? Analysis of the IASLC database. Ann Cardiothorac Surg 2012;1:438-48.

27. Rusch VW, Giroux D, Kennedy C, et al. Initial analysis of the international association for the study of lung cancer mesothelioma database. J Thorac Oncol 2012;7:1631-9.

28. Richards WG. Malignant pleural mesothelioma: predictors and staging. Ann Transl Med 2017;5:243.

29. Waller DA. The staging of malignant pleural mesothelioma: are we any nearer to squaring the circle? Eur J Cardiothorac Surg 2016;49:1648-9.

30. West DG, Walker WS. Staging malignant pleural mesothelioma: additional investigation may not improve accuracy. Eur J Cardiothorac Surg 2011;39:800; author reply 800-1.

31. Zielinski M, Hauer J, Hauer L, et al. Staging algorithm for diffuse malignant pleural mesothelioma. Interact Cardiovasc Thorac Surg 2010;10:185-9.

32. Geltner C, Errhalt P, Baumgartner B, et al. Management of malignant pleural mesothelioma - part 1: epidemiology, diagnosis, and staging : Consensus of the Austrian Mesothelioma Interest Group (AMIG). Wien Klin Wochenschr 2016;128:611-7.

33. de Perrot M, Dong Z, Bradbury P, et al. Impact of tumour thickness on survival after radical radiation and surgery in malignant pleural mesothelioma. Eur Respir J 2017;49:1601428.

34. Goldstraw P, Crowley J, Chansky K, et al. The IASLC Lung Cancer Staging Project: proposals for the revision of the TNM stage groupings in the forthcoming (seventh) edition of the TNM Classification of malignant tumours. J Thorac Oncol 2007;2:706-14.

35. Goldstraw P, Chansky K, Crowley J, et al. The IASLC Lung Cancer Staging Project: Proposals for Revision of the TNM Stage Groupings in the Forthcoming (Eighth) Edition of the TNM Classification for Lung Cancer. J Thorac Oncol 2016;11:39-51.

36. Flores RM, Routledge T, Seshan VE, et al. The impact of lymph node station on survival in 348 patients with surgically resected malignant pleural mesothelioma: implications for revision of the American Joint Committee on Cancer staging system. J Thorac Cardiovasc Surg
2008;136:605-10.

37. Rusch VW, Venkatraman E. The importance of surgical staging in the treatment of malignant pleural mesothelioma. J Thorac Cardiovasc Surg 1996;111:81525; discussion 825-6.

38. Edwards JG, Stewart DJ, Martin-Ucar A, et al. The pattern of lymph node involvement influences outcome after extrapleural pneumonectomy for malignant mesothelioma. J Thorac Cardiovasc Surg 2006;131:981-7.

39. Harrell FE Jr, Lee KL, Mark DB. Multivariable prognostic models: issues in developing models, evaluating assumptions and adequacy, and measuring and reducing errors. Stat Med 1996;15:361-87.

40. Harrell FE Jr, Califf RM, Pryor DB, et al. Evaluating the yield of medical tests. JAMA 1982;247:2543-6.

41. Lococo F, Rena O, Torricelli F, et al. $18 \mathrm{~F}$-fluorodeoxyglucose positron emission tomography in malignant pleural mesothelioma: diagnostic and prognostic performance and its correlation to pathological results. Interact Cardiovasc Thorac Surg 2020;30:593-6.

42. Murphy DJ, Mak SM, Mallia A, et al. Loco-regional staging of malignant pleural mesothelioma by integrated (18)F-FDG PET/MRI. Eur J Radiol 2019;115:46-52.

43. Kitajima K, Doi H, Kuribayashi K, et al. Prognostic value of pretreatment volume-based quantitative (18)F-FDG PET/CT parameters in patients with malignant pleural mesothelioma. Eur J Radiol 2017;86:176-83.

44. Kanemura S, Kuribayashi K, Funaguchi N, et al. Metabolic response assessment with $18 \mathrm{~F}-\mathrm{FDG}-\mathrm{PET} / \mathrm{CT}$ is superior to modified RECIST for the evaluation of response to platinum-based doublet chemotherapy in malignant pleural mesothelioma. Eur J Radiol 2017;86:92-8.

45. Zucali PA, Lopci E, Ceresoli GL, et al. Prognostic and predictive role of [(18) F]fluorodeoxyglucose positron emission tomography (FDG-PET) in patients with unresectable malignant pleural mesothelioma (MPM) treated with up-front pemetrexed-based chemotherapy. Cancer Med 2017;6:2287-96.

46. Cui A, Jin XG, Zhai K, et al. Diagnostic values of soluble mesothelin-related peptides for malignant pleural mesothelioma: updated meta-analysis. BMJ Open 2014;4:e004145.

47. Bonotti A, Simonini S, Pantani E, et al. Serum mesothelin, osteopontin and vimentin: useful markers for clinical monitoring of malignant pleural mesothelioma. Int J Biol Markers 2017;32:e126-31.

48. Franceschini MC, Ferro P, Canessa PA, et al. Mesothelin in serum and pleural effusion in the diagnosis of malignant 
pleural mesothelioma with non-positive cytology.

Anticancer Res 2014;34:7425-9.

49. Judge $S$, Thomas $P$, Govindarajan V, et al. Malignant Peritoneal Mesothelioma: Characterization of the Inflammatory Response in the Tumor Microenvironment. Ann Surg Oncol 2016;23:1496-500.

50. Lamberti M, Capasso R, Lombardi A, et al. Two Different Serum MiRNA Signatures Correlate with the Clinical Outcome and Histological Subtype in Pleural Malignant Mesothelioma Patients. PLoS One 2015;10:e0135331.

51. Shaikh F, Zauderer MG, von Reibnitz D, et al. Improved Outcomes with Modern Lung-Sparing Trimodality Therapy in Patients with Malignant Pleural Mesothelioma. J Thorac Oncol 2017;12:993-1000.

52. Hasegawa S, Okada M, Tanaka F, et al. Trimodality strategy for treating malignant pleural mesothelioma: results of a feasibility study of induction pemetrexed plus cisplatin followed by extrapleural pneumonectomy and postoperative hemithoracic radiation (Japan Mesothelioma Interest Group 0601 Trial). Int J Clin Oncol 2016;21:523-30.

53. Cao C, Tian D, Manganas C, et al. Systematic review of trimodality therapy for patients with malignant pleural mesothelioma. Ann Cardiothorac Surg 2012;1:428-37.

54. Hasani A, Alvarez JM, Wyatt JM, et al. Outcome for patients with malignant pleural mesothelioma referred for
Trimodality therapy in Western Australia. J Thorac Oncol 2009;4:1010-6.

55. Buduhan G, Menon S, Aye R, et al. Trimodality therapy for malignant pleural mesothelioma. The Ann Thorac Surg 2009;88:870-5; discussion 876.

56. Infante $\mathrm{M}$, Morenghi E, Bottoni E, et al. Comorbidity, postoperative morbidity and survival in patients undergoing radical surgery for malignant pleural mesothelioma. Eur J Cardiothorac Surg 2016;50:1077-82.

57. van Zandwijk N, Reid G, Linton A, et al. Radical surgery for malignant pleural mesothelioma: have we identified the appropriate selection tools? Ann Cardiothorac Surg 2012;1:481-6.

58. Cao C, Tian D, Park J, et al. A systematic review and meta-analysis of surgical treatments for malignant pleural mesothelioma. Lung Cancer 2014;83:240-5.

59. Lang-Lazdunski L, Bille A, Lal R, et al. Pleurectomy/ decortication is superior to extrapleural pneumonectomy in the multimodality management of patients with malignant pleural mesothelioma. J Thorac Oncol 2012;7:737-43.

60. Cardillo G, Treasure T. Extrapleural Pneumonectomy Is Not Shown to Be Clinically Effective in the Treatment of Malignant Pleural Mesothelioma. Ann Surg 2017;265:e53.

Cite this article as: $\mathrm{He} \mathrm{J}$, Xu S, Pan H, Li S, He J. Does size matter? - a population-based analysis of malignant pleural mesothelioma. Transl Lung Cancer Res 2020;9(4):1041-1052. doi: $10.21037 /$ tlcr-19-488 


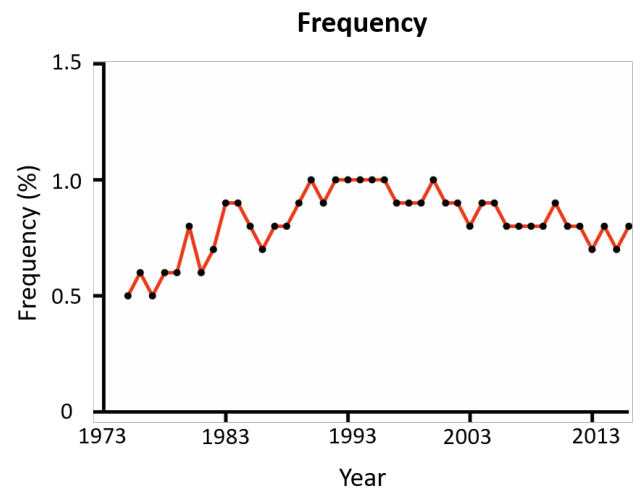

Figure S1 The frequency of malignant pleural mesothelioma in SEER database.
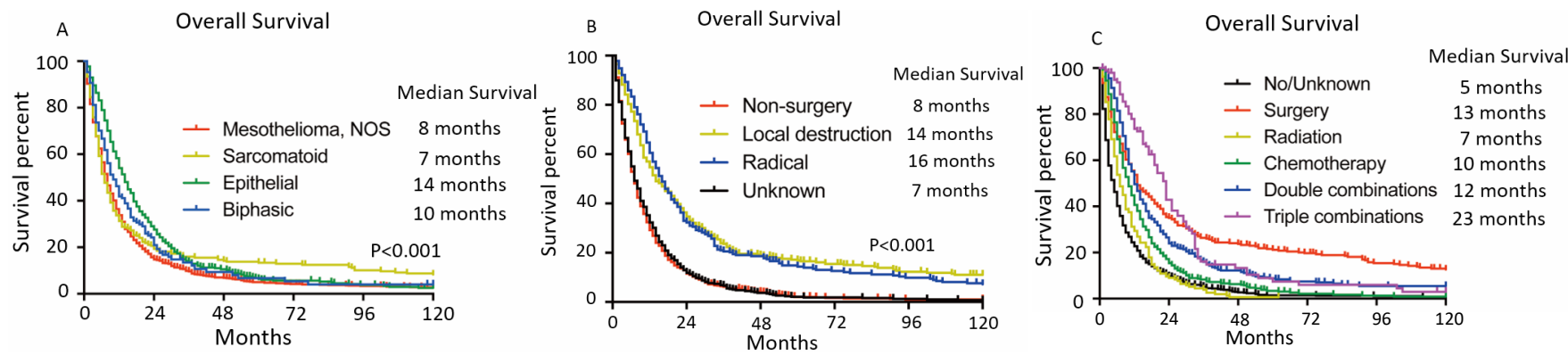

Figure S2 The survival outcomes of each subgroups. (A) Overall survival of pathology subtypes; (B) overall survival of surgery subgroup; (C) overall survival of treatments including multimodality treatments.

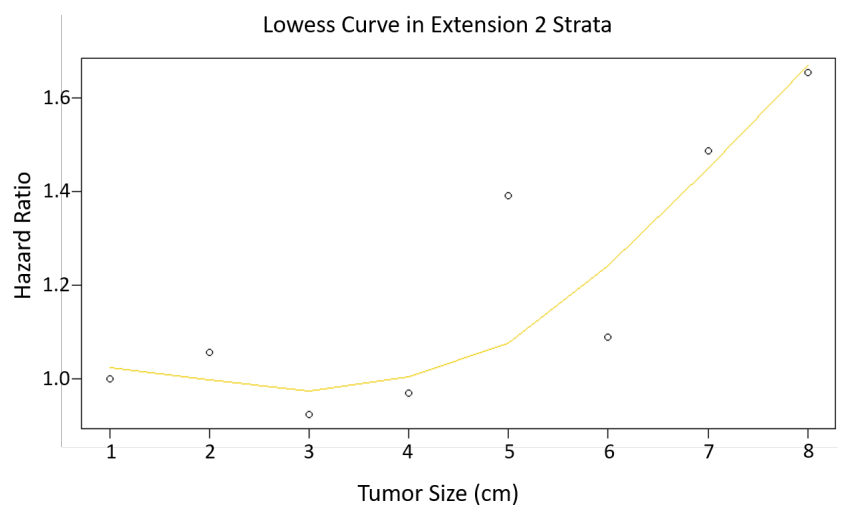

Figure S3 The smooth regression curve of HRs and size intervals in $\mathrm{T} 2$. 
A

Overall Survival

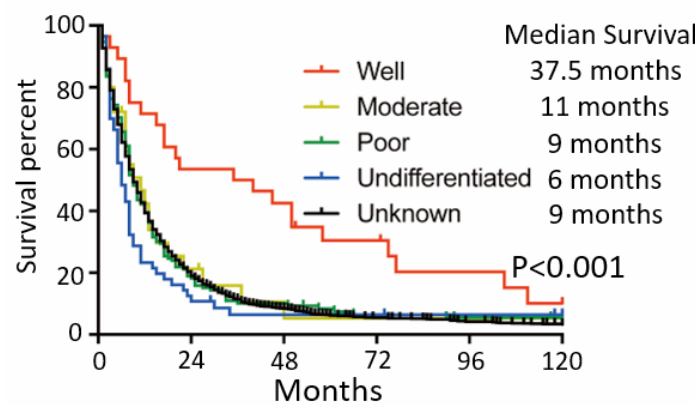

C

Overall Survival

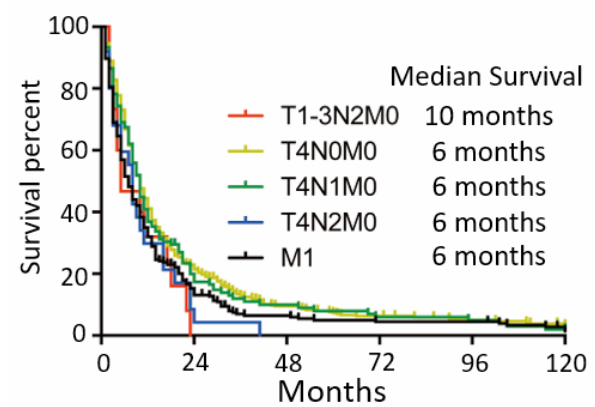

B

Overall Survival

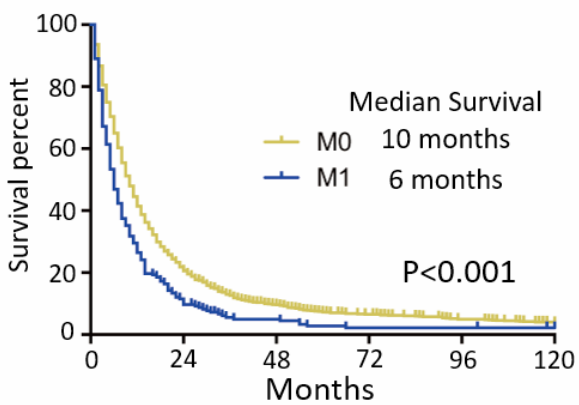

D

Overall Survival

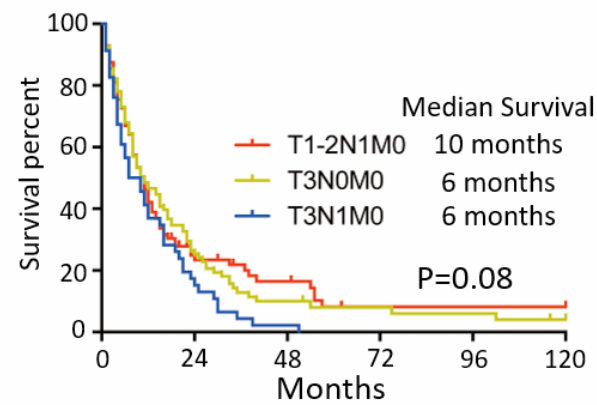

Figure S4 The survival outcomes of different subgroups in the primary cohort. (A) Overall survival of differentiation grade; (B) overall survival of non-metastatic and metastatic patients; (C) overall survival of patients in adjusted Stage IV; (D) overall survival of patients in adjusted Stage III. 
Table S1 The new proposed TNM staging for malignant pleural mesothelioma

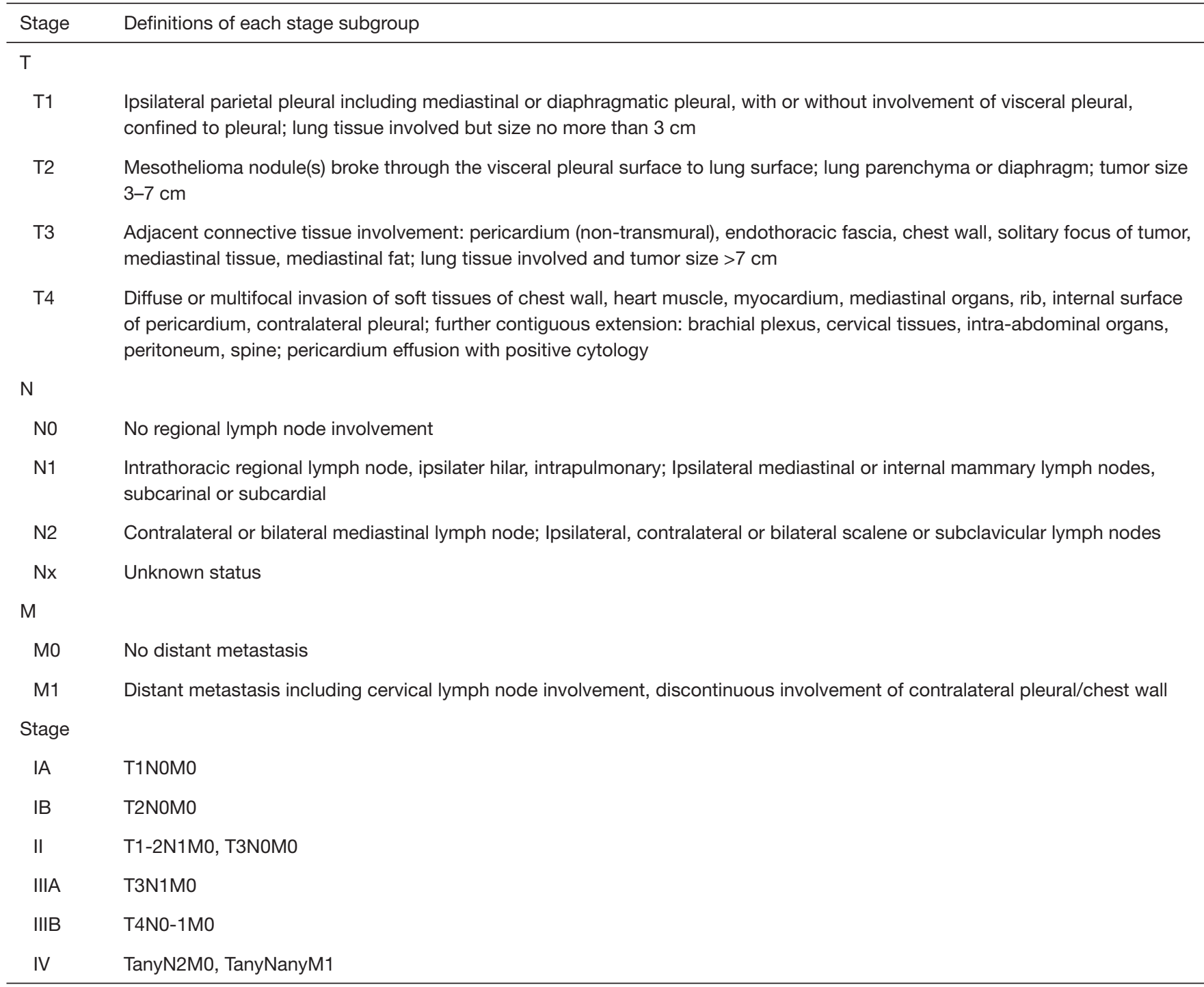

